\section{revista ph}

INSTITUTO ANDALUZ DEL PATRIMONIO HISTÓRICO

\section{Director:}

Román Fernández-Baca Casares

Director del Instituto Andaluz del Patrimonio Histórico

\section{ISSN 1136-1867}

Depósito Legal: CA-267-1994

Distribución nacional e internacional:

2.000 ejemplares

Revista ph es una publicación trimestral del Instituto Andaluz del Patrimonio Histórico que pretende la presentación de un amplio campo de informaciones, noticias y opiniones con el objeto de difundir y fomentar el debate sobre cuestiones de relevancia en torno al patrimonio cultural La totalidad de su contenido no debe ser intepreta do como el punto de vista cel Instituto Andaluz deI Patrimonio Historico, a menos que se especifique explicitamente.

Por razones de espacio y pertinencia, la redacción podrá reducir las contribuciones, sin menoscabo del contenido sustancial de dichas aportaciones.

Las recomendaciones para la participación en la revista pueden ser consultadas en la web institucional www.iaph.es/nav/boletinph

Salvo que se indique lo contrario, esta obra está bajo una Salvo que se indique lo contrario, esta obra está bajo una
licencia Reconocimiento-NoComercial-SinObraDerivada 3.0 licencia Reconocimiento-NoCor

Usted es libre de copiar, distribuir y comunicar públicamente la obra bajo las condiciones siguientes: - Reconocimiento. Debe reconocer los créditos de la obra de la manera especificada por el autor o el licenciador. - No comercial. No puede utilizar esta obra para fines comerciales.

- Sin obras derivadas. No se puede alterar transformar generar una obra derivada a partir de esta obra. Al reutilizar o distribuir la obra, tiene que dejar muy claro los términos de la licencia de esta obra.

Alguna de estas condiciones puede no aplicarse si se obtiene el permiso del titular de los derechos de autor.

Los derechos derivados de usos legitimos u otras limitaciones reconocidas por ley no se ven afectados por lo anterior. La licencia completa está disponible en:

http://creativecommons.org/licenses/by-nc-nd/3.0/es/

legalcode.es

\title{
Editorial
}

\section{Un nuevo sistema para planificar y actuar en la cultura}

Decia Italo Calvino en sus seis propuestas para el próximo milenio que en un tiempo tan dinámico, y confuso, la solución de problemas en cualquier orden dependería de cuatro principios básicos: la agilidad, el aumento de nuestra capacidad para establecer conexiones, la visibilidad y la flexibilidad. Hablaba de poesía, pero su diagnóstico fue tan certero, que las propuestas son válidas para cualquier ámbito de nuestras vidas. También para las instituciones culturales, la naturaleza dinámica del tiempo que vivimos hace necesario el desarrollo de nuevas formas de organización y planificación, abandonando la rigidez de estructuras que dificultan la actualización. Agilidad a la hora de responder y articular propuestas; conectividad, para establecer alianzas; visibilidad para reconocerse, proyectarse y ser reconocidos en ámbitos complejos, y la flexibilidad entendida como la capacidad para convivir en la diferencia y ser receptivos en un mundo cuya base son las relaciones de interconexión e interdependencia.

Entendiendo la dimensión de los cambios de la nueva realidad, el Consejo de Gobierno de la Junta de Andalucía, a propuesta de la Consejería de Cultura, aprobó el 18 de octubre el Sistema de Planificación de Políticas Culturales. El Sistema es el marco para el desarrollo del conjunto de planes, que desarrollan su política. Se constituye en un elemento dinámico, en el que las distintas variables de instituciones y planes, relacionadas entre sí, cumplimentan "una responsabilidad" colectiva en relación con la sociedad, y un compromiso con la ciudadanía, parte esencial de los procesos culturales. En su origen se concreta en los planes generales que desarrollan la misión de la Consejeria, en relación con la tutela del patrimonio y las políticas de impulso a la creación, de acuerdo a la nueva realidad. A partir de ellos, los planes especiales que avanzan en políticas concretas; los propios de cada sector, y los planes directores y anuales de las instituciones.

La experiencia en planificación de la Consejería de Cultura ha sido rica en matices y en soluciones necesarias adaptadas a cada tiempo. Pero, mientras todo alrededor cambia, ni los discursos, ni los conceptos, ni los métodos de planificación pueden convertirse en recurrentes. El Sistema supone la extensión de una cultura de elaboración y renovación de planes dentro de un mismo marco organizativo y estratégico; manteniendo el equilibrio entre la necesaria autonomía de cada institución y la coherencia del conjunto.

Planificar para abordar con inmediatez las dificultades no es hoy día una opción, sino una prioridad. Dice un proverbio de Bali que "si te pasas toda la mañana afilando un lápiz, cuando llegue la tarde en vez de dibujar recogerás astillitas". No hay un tiempo para planificar, y otro para actuar. Las dos son hoy, más que nunca, caras de la misma moneda, y han de integrarse simultáneamente en la dinámica de las organizaciones. En ese sentido, el Sistema propone abordar los retos que plantea la realidad de cada momento, activando la inteligencia colectiva y gestionando adecuadamente los recursos y el capital de conocimiento de la propia organización y su entorno. 